\title{
Aqueous extract of Cordyceps alleviates cerebral ischemia-induced short-term memory impairment in gerbils
}

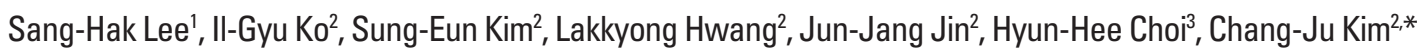 \\ 'Department of Life Science, College of Science \& Engineering, Cheongju University, Cheongju, Korea \\ ${ }^{2}$ Department of Physiology, College of Medicine, Kyung Hee University, Seoul, Korea \\ ${ }^{3}$ Division of Leisure \& Sports Science, Department of Exercise Prescription, Dongseo University, Busan, Korea
}

Cerebral ischemia is caused by reduced cerebral blood flow due to a transient or permanent cerebral artery occlusion. Ischemic injury in the brain leads to neuronal cell death, and eventually causes neurological impairments. Cordyceps, the name given to the fungi on insects, has abundant useful natural products with various biological activities. Cordyceps is known to have nephroprotective, hepatoprotective, anti-inflammatory, antioxidative, and antiapoptotic effects. We investigated the effects of Cordyceps on short-term memory, neuronal apoptosis, and cell proliferation in the hippocampal dentate gyrus following transient global ischemia in gerbils. For this study, a step-down avoidance test, terminal deoxynucleotidyl transferase-mediated dUTP nick end labeling assay, immunohistochemistry for caspase-3 and 5-bromo-2'-de-oxyuridine, and western blot for $\mathrm{Bax}, \mathrm{Bcl}-2$, brain-derived neurotrophic fac- tor (BDNF), and tyrosin kinase B were performed. In the present study, Cordyceps alleviated cerebral ischemia-induced short-term memory impairment. Cordyceps showed therapeutic effects through inhibiting cerebral ischemia-induced apoptosis in the hippocampus. Cordyceps suppressed cerebral ischemia-induced cell proliferation in the hippocampal dentate gyrus due to the reduced apoptotic neuronal cell death. Cordyceps treatment also enhanced BDNF and TrkB expressions in the hippocampus of ischemic gerbils. It can be suggested that Cordyceps overcomes cerebral ischemia-induced neuronal apoptosis, thus facilitates recovery following cerebral ischemia injury.

Keywords: Cerebral ischemia, Cordyceps, Short-term memory, Apoptosis

\section{INTRODUCTION}

Stroke is third most common cause of death following heart attack and cancer in the major industrialized countries. Cerebral ischemia is caused by reduced cerebral blood flow due to a transient or permanent cerebral artery occlusion (Leker and Shohami, 2002). Ischemic injury in the brain leads to neuronal cell death, and eventually causes neurological impairments (Benchoua et al., 2001; Lee et al., 2003). Pyramidal neurons in the hippocampal CA1 region are particularly vulnerable to ischemic injury (Sugawara et al., 2002).

Apoptosis is an important mechanism leading after cerebral ischemia. Apoptosis, programmed cell death, is an ATP-depen- dent physiological process, which is important for tissue homeostasis and pathological conditions. Nevertheless, inappropriate or excessive apoptosis has been implicated in several neurogoical disorders (Ko et al., 2009; Lee et al., 2003). Terminal deoxynucleotidyl transferase-mediated dUTP nick end labeling (TUNEL) assay detects the characteristic of apoptotic cell death, DNA fragmentation (Gavrieli et al., 1992). Another important characteristic of apoptosis is caspases activation. Caspase- 3 is one of the most widely studied caspases, and it is a key executor of apoptosis (Cohen, 1997). Besides caspases, the Bcl-2 family proteins also play important roles in regulation of apoptosis. The Bcl-2 family proteins are classified into antiapoptotic proteins, including $\mathrm{Bcl}-2$ and $\mathrm{Bcl}-$ $\mathrm{XL}$, and pro-apoptotic proteins, such as Bax and Bid. The balance

\footnotetext{
${ }^{*}$ Corresponding author: Chang-Ju Kim (iD http://orcid.org/0000-0003-4749-5795 Department of Physiology, College of Medicine, Kyung Hee University, 26 Kyungheedae-ro, Dongdaemun-gu, Seoul 02447, Korea Tel: +82-2-961-0407, Fax: +82-2-964-2195, E-mail: changju@kgu.ac.kr Received: February 4, 2016 / Accepted: April 5, 2016
}

This is an Open Access article distributed under the terms of the Creative Commons Attribution Non-Commercial License (http://creativecommons.org/licenses/by-nc/4.0/) which permits unrestricted non-commercial use, distribution, and reproduction in any medium, provided the original work is properly cited. 
between pro-apoptotic and antiapoptotic Bcl-2 family members determines the mitochondrial response to apoptotic stimuli (Upadhyay et al., 2003).

Several factors, such as genes, neurotransmitter, and neurotrophins, have been suggested to be involved in the dysfunction of memory and cognitive function following brain insults. Among them, brain-derived neurotrophic factor (BDNF) is a small dimeric protein and works through high affinity binding with its receptor, tyrosin kinase B (TrkB). BDNF modulates neuronal growth and survival, and BNDF is implicated in learning and memory processes. Especially, BDNF is considered to be implicated in the pathophysiology of several brain injury patients (Ke and Zhang, 2013; Simon et al., 2016). Reduction of BDNF level in the hippocampus impairs learning and memory performance in animals (Kim et al., 2013; Sairanen et al., 2005).

Cordyceps, the name given to the fungi on insects, has abundant useful natural products with various biological activities. Many bioactive constituents in the Cordyceps, such as polysaccharides, cordycepin, mannitol, aminophenol, and ergosterol have been reported (Yao et al., 2015). Chemical constituents extracted from Cordyceps have various pharmacological actions, including nephroprotective, hepatoprotective, anti-inflammatory, antioxidative, and antiapoptotic effects (Jeong et al., 2010; Yamaguchi et al., 2000; Yue et al., 2013).

Functional roles of the Cordyceps have widely been documented, however the effects of Cordyceps on memory deterioration and apoptotic neuronal cell death induced by cerebral ischemia have not been reported. In the present study, we investigated the effects of Cordyceps on short-term memory, neuronal apoptosis, and cell proliferation in the hippocampal dentate gyrus following transient global ischemia in gerbils. For this study, a step-down avoidance test, TUNEL assay, immunohistochemistry for caspase- 3 and 5-bromo-2'-deoxyuridine (BrdU), and western blot for Bax, Bcl2, BDNF, and TrkB were performed.

\section{MATERIALS AND METHODS}

\section{Preparation of aqueous extract of Cordyceps}

Cordyceps was supplied from GCordy (Seoul, Korea). To obtain the aqueous extract of Cordyceps, $50 \mathrm{~g}$ of Cordyceps was added to distilled water, and extraction was performed by heating at $90^{\circ} \mathrm{C}$ for $2 \mathrm{hr}$, concentrating with rotary evaporator (Eyela, Tokyo, Japan) and lyophilizing by a drying machine (Eyela) for $24 \mathrm{hr}$. The resulting powder, weighting $11.5 \mathrm{~g}$ (yield of $23 \%$ ) was diluted to the concentrations needed with autoclaved distilled water and fil- tered through a $0.45-\mu \mathrm{m}$ syringe filter before use.

\section{Animals and treatments}

Adult male Mongolian gerbils (14 weeks old) were used in this experiment. The experimental procedures were performed in accordance with the animal care guidelines of the National Institutes of Health (NIH) and the Korean Academy of Medical Sciences. The gerbils were housed under controlled temperature $\left(23^{\circ} \mathrm{C} \pm 2^{\circ} \mathrm{C}\right)$ and lighting $(08: 00$ a.m. to 20:00 p.m.) conditions with food and water available ad libitum. The animals were randomly divided into the following five groups $(n=10$ in each group): sham-operation group, cerebral ischemia-induced group, cerebral ischemia-induced and $0.001-\mathrm{mg} / \mathrm{kg}$ Cordyceps-treated group, cerebral ischemia-induced and $0.01-\mathrm{mg} / \mathrm{kg}$ Cordyceps-treated group, and cerebral ischemia-induced and $0.1-\mathrm{mg} / \mathrm{kg}$ Cordyceps-treated group. All gerbils received 50-mg/kg BrdU (Sigma Chemical Co., St. Louis, MO, USA) intraperitoneally once a day for 3 consecutive days, starting one day after surgery. Gerbils in the Cordyceps-treated groups received Cordyceps orally once a day for 14 consecutive days, starting one day after surgery. Gerbils in the sham-operation group and in the cerebral ischemia-induced group received an equal amount of distilled water for the same duration.

\section{Induction of transient global ischemia}

Transient global ischemia was induced with a previously described surgical procedure (Ko et al., 2009). In brief, gerbils were anesthetized with Zoletil $50(10 \mathrm{mg} / \mathrm{kg}$, intraperitoneally; Vibac Laboratories, Carros, France). Following bilateral neck incisions, both common carotid arteries were exposed and occluded with aneurysm clips for $7 \mathrm{~min}$. The clips were then removed to restore cerebral blood flow. Body and rectal temperature was maintained at $36^{\circ} \mathrm{C} \pm 0.5^{\circ} \mathrm{C}$ during surgery using Homeothermic Blanket Control Unit (Harvard Apparatus, Massachusetts, MA, USA) that enveloped the body and the head. After recovery, the animals were monitored for an additional $2 \mathrm{hr}$ to prevent hypothermia. The animals in the sham-operation group were treated identically, except that the common carotid arteries were not occluded after the neck incisions.

\section{Step-down avoidance test}

The latency time of the step-down avoidance test was determined to evaluate short-term memory, using a previously described method (Ko et al., 2009). Gerbils were trained in a stepdown avoidance test 13 days after cerebral ischemia inducing op- 
eration. Two hours after training, the latency (sec) of the animals in each group was determined. Gerbils were placed $7 \times 25-\mathrm{cm}$ platform $2.5 \mathrm{~cm}$ high. The platform faced a $42 \times 25-\mathrm{cm}$ grid of parallel $0.1 \mathrm{~cm}$-caliber stainless steel bars spaced $1 \mathrm{~cm}$ apart. In training sessions, the animals received $0.5 \mathrm{~mA}$, scramble foot shock for 2 sec immediately upon stepping down. The interval of gerbils stepping down and placing all four paws on the grid was defined as the latency time. Latency over $300 \mathrm{sec}$ was counted as 300 sec.

\section{Tissue preparation}

The animals were sacrificed immediately after determining the latency of the step-down avoidance test. Gerbils were anesthetized using Zoletil $50(10 \mathrm{mg} / \mathrm{kg}$, intraperitoneally; Vibac Laboratories), transcardially perfused with $50 \mathrm{mM}$ phosphate-buffered saline (PBS), and fixed with a freshly prepared solution consisting of 4\% paraformaldehyde in $100 \mathrm{mM}$ phosphate buffer (PB, $\mathrm{pH} 7.4$ ). Brains were dissected, and storage overnight same fixative, then it was transferred to $30 \%$ sucrose for cryoprotection. For the immunohistochemistry, the slices were coronal sectioned at $40 \mu \mathrm{m}$ thick using a cryostat (Leica, Nussloch, Germany). The sections of 2.5 to $2.7 \mathrm{~mm}$ posterior from the bregma were used for immunohistochemistry. Ten slice sections in the hippocampus were collected from each gerbil.

\section{TUNEL staining}

To visualize DNA fragmentation, a marker of apoptotic cell death, TUNEL staining was performed, as the previously described method (Jin et al., 2014; Ko et al., 2009) using an in situ cell death detection kit (Roche, Mannheim, Germany). Brain tissues were denatured for $10 \mathrm{~min}$ in boiling $10 \mathrm{mM}$ citric acid (pH 6.0) and then placed in room temperature for $10 \mathrm{~min}$. Sections were postfixed in ethanol-acetic acid (2:1) and rinsed. Subsequently, they were incubated with proteinase $\mathrm{K}(100 \mu \mathrm{g} / \mathrm{mL})$, rinsed, incubated in 3\% $\mathrm{H}_{2} \mathrm{O}_{2}$, permeabilized with $0.5 \%$ Triton X-100, rinsed again, and incubated in TUNEL reaction mixture. The sections were then rinsed and visualized using Converter-POD with $0.03 \%$ 3,3'-diaminobenzidine (DAB). Mayer's hematoxylin (DAKO, Glostrup, Denmark) was used for counter-staining, and the sections were finally mounted onto gelatin-coated slides. The slides were air dried overnight at room temperature, and coverslips were mounted using Permount (Fisher Scientific, New Jersey, NJ, USA).

\section{Immunohistochemistry for caspase-3}

Immunohistochemistry was conducted to evaluate the caspase-3 expression in the hippocampal dentate gyrus, according to the previously described methods (Jin et al., 2014; Ko et al., 2009). Free-floating tissue sections were incubated overnight with mouse anti-caspase-3 antibody (1:500; Santa Cruz Biotechnology, Santa Cruz, CA, USA) at a dilution of 1:1,000, and the sections were then incubated for $1 \mathrm{hr}$ with biotinylated antimouse for caspase- 3 secondary antibody (1:200; Vector Laboratories, Burlingame, CA, USA). Next, the sections were incubated with avidin-biotin-peroxidase complex (Vector Laboratories) for $1 \mathrm{hr}$ at room temperature. For staining, the sections were incubated in a reaction mixture consisting of $0.03 \% \mathrm{DAB}$ and $0.03 \% \mathrm{H}_{2} \mathrm{O}_{2}$ for $5 \mathrm{~min}$. The sections were finally mounted onto gelatin-coated slides. The slides were air dried overnight at room temperature, and coverslips were mounted using Permount (Fisher Scientific).

\section{Immunohistochemistry for BrdU}

To detect of newly generated cells in the dentate gyrus, BrdU-specific immunohistochemistry was performed, according to the previously described method (Kim et al., 2010; Ko et al., 2009). The sections were first permeabilized by incubation in $0.5 \%$ Triton X-100 in PBS for 20 min, then pretreated in 50\% formamide- $2 \times$ standard saline citrate at $65^{\circ} \mathrm{C}$ for $2 \mathrm{hr}$, denaturated in $2 \mathrm{~N} \mathrm{HCl}$ at $37^{\circ} \mathrm{C}$ for $30 \mathrm{~min}$, and rinsed twice in $100 \mathrm{mM}$ sodium borate ( $\mathrm{pH}$ 8.5). Afterwards, the sections were incubated overnight at $4^{\circ} \mathrm{C}$ with $\mathrm{BrdU}$-specific mouse monoclonal antibody (1:600; Roche). The sections were then washed three times with PBS and incubated for $1 \mathrm{hr}$ with a biotinylated mouse secondary antibody (1:200; Vector Laboratories). Then, the sections were incubated for another $1 \mathrm{hr}$ with avidin-peroxidase complex (1:100; Vector Laboratories). For visualization, the sections were incubated in $50 \mathrm{mM}$ Tris- $\mathrm{HCl}(\mathrm{pH} 7.6)$ containing $0.03 \% \mathrm{DAB}, 40 \mathrm{mg} /$ $\mathrm{mL}$ nickel chloride, and $0.03 \% \mathrm{H}_{2} \mathrm{O}_{2}$ for $5 \mathrm{~min}$. After BrdU-specific staining, determination of the differentiation of BrdU-positive cells was performed on same section using a mouse antineuronal nucleic (NeuN) antibody (1:1,000; Chemicon International, Temecula, CA, USA). The sections were washed three times with PBS, incubated for $\mathrm{l}$ hr with a biotinylated anti-mouse secondary antibody, and processed with VECTASTAIN ABC Kit (Vector Laboratories). For staining, the sections were incubated in a reaction mixture consisting of $0.03 \% \mathrm{DAB}$ and $0.03 \% \mathrm{H}_{2} \mathrm{O}_{2}$ for 5 $\mathrm{min}$. The sections were finally mounted onto gelatin-coated slides. The slides were air dried overnight at room temperature, and coverslips were mounted using Permount (Fisher Scientific). 


\section{Western blotting}

Western blot for the $\mathrm{Bcl}-2$, Bax, BDNF, and TrkB was performed, according to the previously described method (Kim et al., 2010; Kim et al., 2015). The hippocampal tissues were dissected and collected, and then were immediately frozen at $-70^{\circ} \mathrm{C}$. The right hemisphere were homogenized on ice, and lysed in a lysis buffer containing $50 \mathrm{mM} \mathrm{N}$-2-hydroxyethylpiperazine-N-2-ethanesulfonic acid (pH 7.5), $150 \mathrm{mM} \mathrm{NaCl}, 10 \%$ glycerol, $1 \%$ Triton X-100, 1 mM PMSF, 1 mM ethyleneglycol-bis-(b-aminoethylether)-N,N,N',N'-tetraacetic acid (EGTA), $1.5 \mathrm{mM} \mathrm{MgCl} 2$ $\cdot 6 \mathrm{H}_{2} \mathrm{O}, 1 \mathrm{mM}$ sodium orthovanadate, and $100 \mathrm{mM}$ sodium fluoride. Protein content was measured using a Bio-Rad colorimetric protein assay kit (Hercules, CA, USA). Protein samples $(30 \mu \mathrm{g})$ were separated on sodium dodecyl sulfate-polyacrylamide gel and transferred onto a nitrocellulose membrane. The membranes were incubated with 5\% skim milk in Tris-buffered saline containing $0.1 \%$ Tween-20 and then incubated overnight at $4{ }^{\circ} \mathrm{C}$ with the following primary antibodies: mouse anti- $\beta$-actin antibody, anti-Bcl-2, anti-Bax, and rabbit anti-BDNF, anti-TrkB (1:1,000; Santa Cruz Biotechnology). Subsequently, membranes were incubated for $1 \mathrm{hr}$ with attempt secondary antibodies (1:2,000; Vector Laboratories), and ban detection was performed using the enhanced chemiluminescence detection kit (Santa Cruz Biotechnology). To compare the relative expression of proteins, the detected bands were calculated densitometrically using Molecular Analyst, ver. 1.4.1 (Bio-Rad).

\section{Data analysis}

For confirming the expressions of $\mathrm{Bcl}-2$, Bax, BDNF, and TrkB the detected bands were calculated densitometrically using Image-Pro Plus image analysis system (Media Cyberbetics Inc., Silver Spring, MD, USA). The numbers of TUNEL-positive and caspase-3-positive cells in the CA1 region were counted hemilaterally through a light microscope (Olympus, Tokyo, Japan). The numbers of TUNEL-positive and caspase-3-positive cells were expressed as the number of cells per $\mathrm{mm}^{2}$ of the CA1 region. The number of BrdU-positive cells in the granular layer of the dentate gyrus was counted hemilaterally through a light microscope (Olympus). The number of BrdU-positive cells was expressed as the number of cells per $\mathrm{mm}^{2}$ of granular area in the dentate gyrus. Statistical analysis was performed using one-way analysis of variance followed by Duncan post hoc test, and the results are expressed as the mean \pm standard error of the mean. Significance was set as $P<0.05$.

\section{RESULTS}

\section{Effect of Cordyceps on short-term memory in the step- down avoidance test}

The latencies of the step-down avoidance test are presented in Fig. 1. The latency time was $116.60 \pm 14.39 \mathrm{sec}$ in the sham-operation group, $43.10 \pm 11.07 \mathrm{sec}$ in the cerebral ischemia-induced group, $93.90 \pm 16.80 \mathrm{sec}$ in the cerebral ischemia-induced and $0.001-\mathrm{mg} / \mathrm{kg}$ Cordyceps-treated group, $76.00 \pm 16.09 \mathrm{sec}$ in the cerebral ischemia-induced and $0.01-\mathrm{mg} / \mathrm{kg}$ Cordyceps-treated group, and $52.20 \pm 10.32 \mathrm{sec}$ in the cerebral ischemia-induced and $0.1-\mathrm{mg} / \mathrm{kg}$ Cordyceps-treated group.

These results showed that short-term memory was disturbed by induction of ischemic injury, and Cordyceps treatment alleviated cerebral ischemia-induced short-term memory impairment.

\section{Effect of Cordyceps on TUNEL-positive cells in the hippocampal CA1 region}

Photomicrographs of TUNEL-positive cells in the hippocampal CA1 region are presented in Fig. 2. The number of TUNEL-positive cells was $28.68 \pm 4.50 / \mathrm{mm}^{2}$ in the sham-operation group, $202.34 \pm 24.13 / \mathrm{mm}^{2}$ in the cerebral ischemia-induced group, $81.53 \pm 15.95 / \mathrm{mm}^{2}$ in the cerebral ischemia-induced and 0.001 $\mathrm{mg} / \mathrm{kg}$ Cordyceps-treated group, $109.63 \pm 9.52 / \mathrm{mm}^{2}$ in the cerebral ischemia-induced and $0.01-\mathrm{mg} / \mathrm{kg}$ Cordyceps-treated group, and $143.54 \pm 23.10 / \mathrm{mm}^{2}$ in the cerebral ischemia-induced and

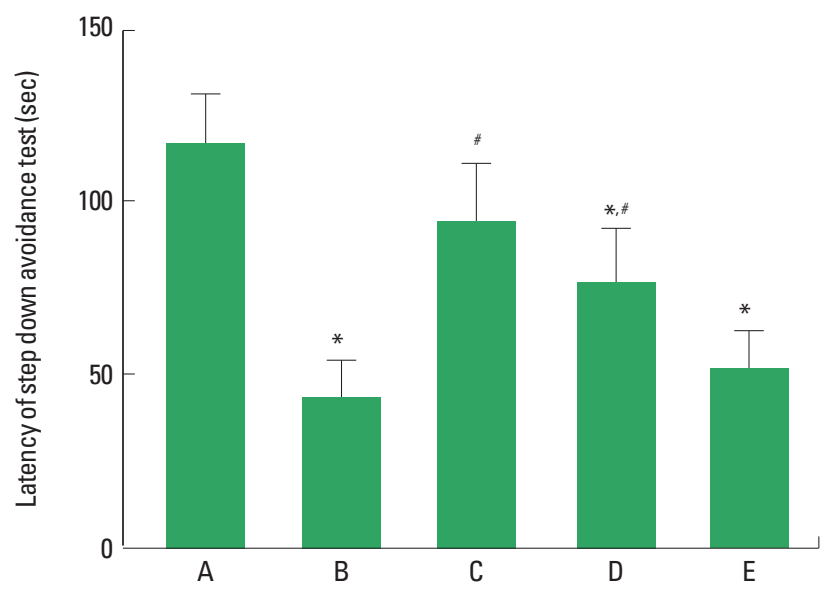

Fig. 1. Effect of Cordyceps on latency in the step-down avoidance test. (A) Sham-operation group, (B) cerebral ischemia-induced group, (C) cerebral ischemia-induced and $0.001-\mathrm{mg} / \mathrm{kg}$ Cordyceps-treated group, (D) cerebral ischemia-induced and 0.01-mg/kg Cordyceps-treated group, (E) cerebral ischemia-induced and $0.1-\mathrm{mg} / \mathrm{kg}$ Cordyceps-treated group. ${ }^{*} P<0.05$ compared to the sham-operation group. ${ }^{\#} P<0.05$ compared to the cerebral ischemia-induced group. 


\section{1 -mg/kg Cordyceps-treated group.}

These results showed that ischemic injury enhanced apoptotic cell death in the hippocampal CA1 region, and Cordyceps treatment suppressed cerebral ischemia-induced apoptosis.

\section{Effect of Cordyceps on caspase-3 expression in the hippocampal CA1 region}

Photomicrographs of caspase-3-positive cells in the hippocampal CA1 region are presented in Fig. 3. The number of caspase3 -positive cells was $34.71 \pm 3.41 / \mathrm{mm}^{2}$ in the sham-operation group, $143.19 \pm 12.41 / \mathrm{mm}^{2}$ in the cerebral ischemia-induced group, $66.80 \pm 8.34 / \mathrm{mm}^{2}$ in the cerebral ischemia-induced and $0.001-\mathrm{mg} / \mathrm{kg}$ Cordyceps-treated group, $99.12 \pm 6.28 / \mathrm{mm}^{2}$ in the cerebral ischemia-induced and $0.01-\mathrm{mg} / \mathrm{kg}$ Cordyceps-treated group, and $98.57 \pm 9.03 / \mathrm{mm}^{2}$ in the cerebral ischemia-induced and $0.1-\mathrm{mg} / \mathrm{kg}$ Cordyceps-treated group.
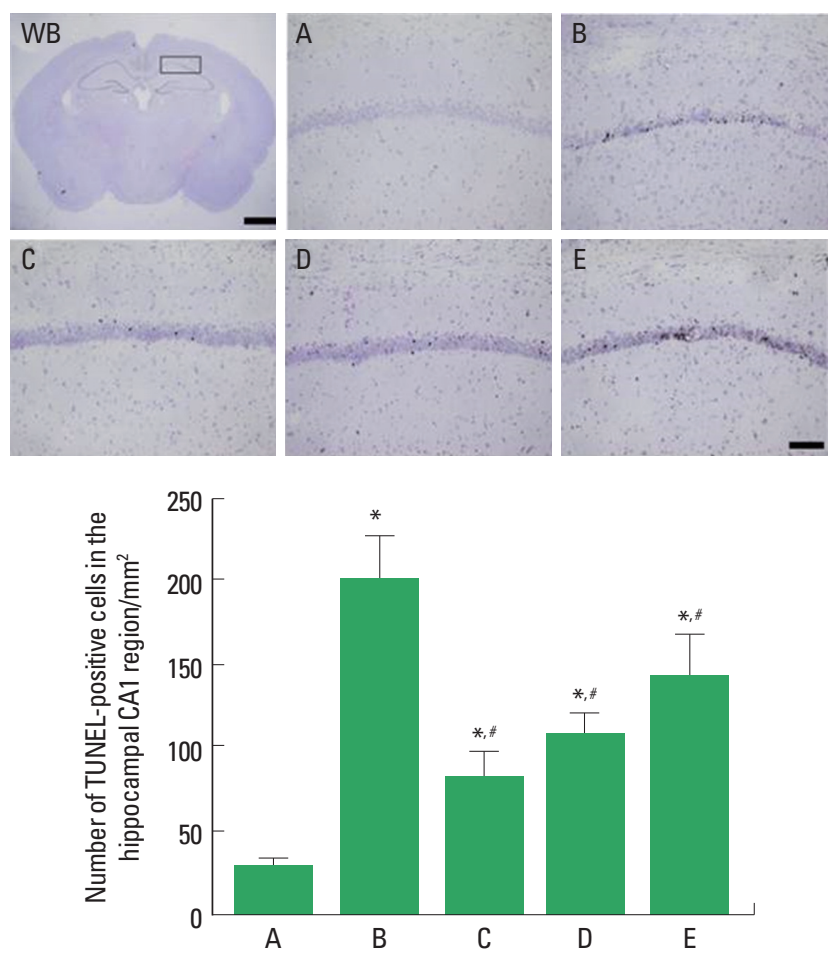

Fig. 2. Effect of Cordyceps on DNA fragmentation in the hippocampal CA1 region. Upper: Photomicrographs of terminal deoxynucleotidyl transferase-mediated dUTP nick end labeling (TUNEL)-positive cells in the hippocampal CA1 region. (WB) Whole brain, (A) sham-operation group, $(B)$ cerebral ischemia-induced group, (C) cerebral ischemia-induced and 0.001-mg/kg Cordyceps-treated group, (D) cerebral ischemia-induced and $0.01-\mathrm{mg} / \mathrm{kg}$ Cordyceps-treated group, (E) cerebral ischemia-induced and 0.1-mg/kg Cordyceps-treated group. The scale bars represent $25 \mu \mathrm{m}$ (WB) and $150 \mu \mathrm{m}$ (A-E). Lower: Number of TUNEL-positive cells in each group. ${ }^{*} P<0.05$ compared to the sham-operation group. ${ }^{\sharp} P<0.05$ compared to the cerebral ischemia-induced group.
These results showed that ischemic injury enhanced caspase-3 expression in the hippocampal CA1 region, and Cordyceps treatment suppressed cerebral ischemia-induced caspase-3 expression.

\section{Effect of Cordyceps on cell proliferation in the hippocampal dentate gyrus}

Photomicrographs of BrdU-positive cells in the hippocampal dentate gyrus are presented in Fig. 4. The number of BrdU-positive cells was $45.85 \pm 10.71 / \mathrm{mm}^{2}$ in the sham-operation group, $212.08 \pm 21.62 / \mathrm{mm}^{2}$ in the cerebral ischemia-induced group, $88.54 \pm 9.51 / \mathrm{mm}^{2}$ in the cerebral ischemia-induced and 0.001 $\mathrm{mg} / \mathrm{kg}$ Cordyceps-treated group, $105.62 \pm 7.47 / \mathrm{mm}^{2}$ in the cerebral ischemia-induced and $0.01-\mathrm{mg} / \mathrm{kg}$ Cordyceps-treated group, and $134.50 \pm 24.92 / \mathrm{mm}^{2}$ in the cerebral ischemia-induced and $0.1-\mathrm{mg} / \mathrm{kg}$ Cordyceps-treated group.

These results showed that ischemic injury enhanced cell prolif-
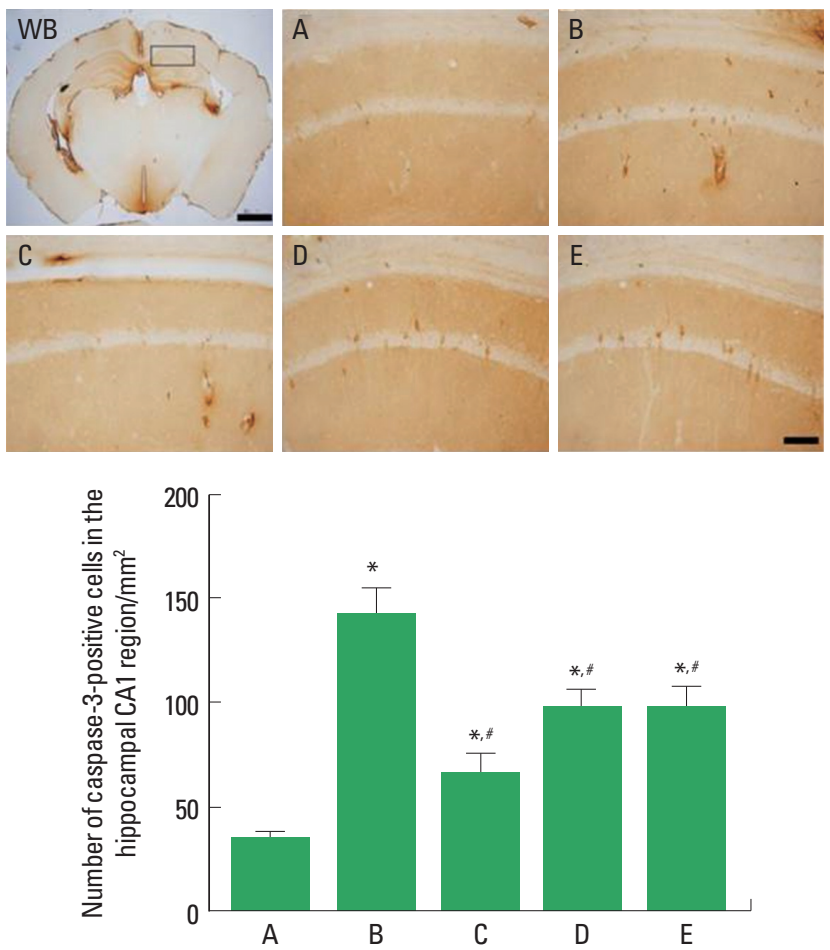

Fig. 3. Effect of Cordyceps on caspase-3 expressions in the hippocampal CA1 region. Upper: Photomicrographs of caspase-3-positive cells in the hippocampal CA1 region. (WB) Whole brain, (A) sham-operation group, (B) cerebral ischemia-induced group, (C) cerebral ischemia-induced and 0.001-mg/kg Cordyceps-treated group, (D) cerebral ischemia-induced and $0.01-\mathrm{mg} / \mathrm{kg}$ Cordyceps-treated group, (E) cerebral ischemia-induced and $0.1-\mathrm{mg} / \mathrm{kg}$ Cordyceps-treated group. The scale bars represent $25 \mu \mathrm{m}(\mathrm{WB})$ and $150 \mu \mathrm{m}(\mathrm{A}-\mathrm{E})$. Lower: Number of caspase-3-positive cells in each group. ${ }^{*} P<0.05$ compared to the sham-operation group. ${ }^{\sharp} P<0.05$ compared to the cerebral ischemia-induced group. 

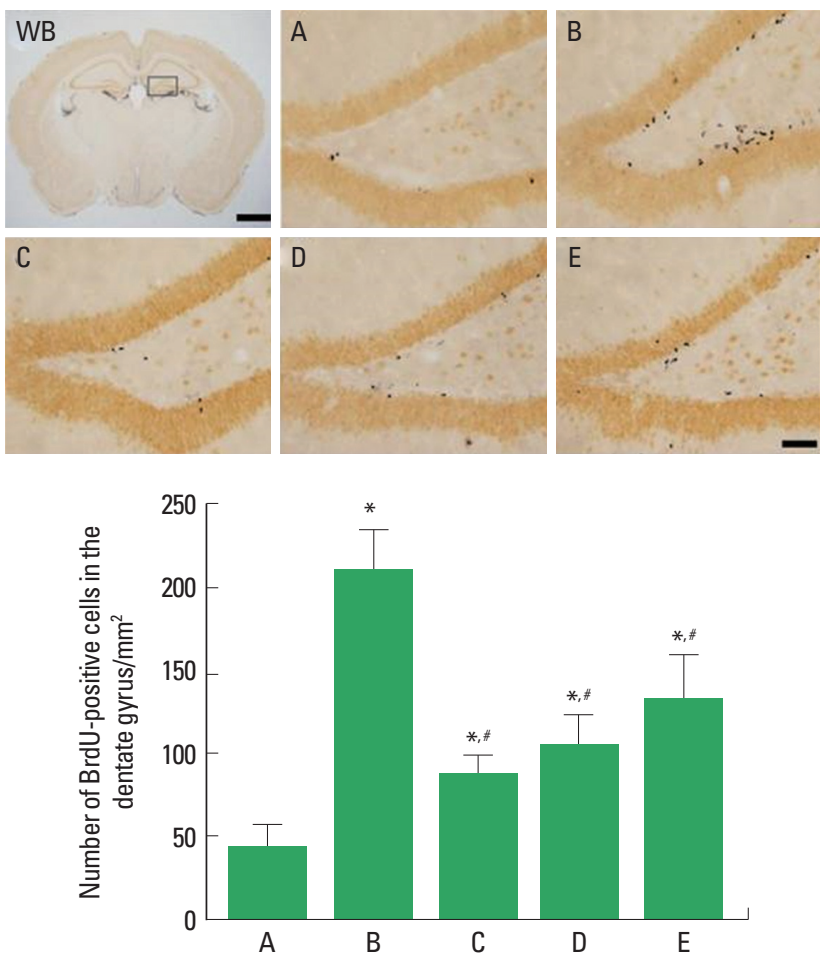

Fig. 4. Effect of Cordyceps on cell proliferation in the hippocampal dentate gyrus. Upper: Photomicrographs of 5-bromo-2'-deoxyuridine (BrdU)-positive cells in the hippocampal dentate gyrus. (WB) Whole brain, (A) sham-operation group, (B) cerebral ischemia-induced group, (C) cerebral ischemia-induced and $0.001-\mathrm{mg} / \mathrm{kg}$ Cordyceps-treated group, (D) cerebral ischemia-induced and 0.01$\mathrm{mg} / \mathrm{kg}$ Cordyceps-treated group, (E) cerebral ischemia-induced and 0.1-mg/kg Cordyceps-treated group. The scale bars represent $25 \mu \mathrm{m}(\mathrm{WB})$ and $150 \mu \mathrm{m}(\mathrm{A}-$ E). Lower: Number of BrdU-positive cells in each group. ${ }^{*} P<0.05$ compared to the sham-operation group. ${ }^{\#} P<0.05$ compared to the cerebral ischemia-induced group.

eration in the hippocampal dentate gyrus region, and Cordyceps treatment suppressed cerebral ischemia-induced cell proliferation.

\section{Effects of Cordyceps on Bax and Bcl-2 expressions in the hippocampus}

To verify the effects of Cordyceps on the expressions of apoptotic proteins, the relative expressions of $\mathrm{Bax}$ and $\mathrm{Bcl}-2$ proteins were ascertained (Fig. 5). When the level of $\mathrm{Bax}(24 \mathrm{kDa})$ in the sham-operation group was set at 1.00, the level of Bax was $5.10 \pm 0.81$ in the cerebral ischemia-induced group, $2.01 \pm 0.31$ in the cerebral ischemia-induced and $0.001-\mathrm{mg} / \mathrm{kg}$ Cordyceps-treated group, $2.34 \pm 0.39$ in the cerebral ischemia-induced and $0.01-\mathrm{mg} / \mathrm{kg}$ Cordyceps-treated group, and $3.90 \pm 0.60$ in the cerebral ischemia-induced and $0.1-\mathrm{mg} / \mathrm{kg}$ Cordyceps-treated group.

When the level of Bcl-2 (26-29 kDa) in the sham-operation group was set at 1.00 , the level of $\mathrm{Bcl}-2$ was $0.51 \pm 0.06$ in the ce- rebral ischemia-induced group, $1.07 \pm 0.07$ in the cerebral ischemia-induced and $0.001-\mathrm{mg} / \mathrm{kg}$ Cordyceps-treated group, $1.19 \pm 0.08$ in the cerebral ischemia-induced and $0.01-\mathrm{mg} / \mathrm{kg}$ Cordyceps-treated group, and $0.80 \pm 0.06$ in the cerebral ischemia-induced and $0.1-\mathrm{mg} / \mathrm{kg}$ Cordyceps-treated group.

When the ratio in the sham-operation group was set as 1.00 , the ratio of Bax to $\mathrm{Bcl}-2$ was $9.81 \pm 1.55$ in the cerebral ischemia-induced group, $1.91 \pm 0.30$ in the cerebral ischemia-induced and $0.001-\mathrm{mg} / \mathrm{kg}$ Cordyceps-treated group, $2.00 \pm 0.33$ in the cerebral ischemia-induced and $0.01-\mathrm{mg} / \mathrm{kg}$ Cordyceps-treated group, and $4.91 \pm 0.76$ in the cerebral ischemia-induced and 0.1$\mathrm{mg} / \mathrm{kg}$ Cordyceps-treated group.

These results showed that induction of cerebral ischemia enhanced the ratio of $\mathrm{Bax}$ to $\mathrm{Bcl}-2$, resulting in facilitation of apoptosis in the hippocampus. However, Cordyceps treatment suppressed the ratio of Bax to Bcl-2, resulting in alleviation of apoptosis in the hipocampus.

\section{Effects of Cordyceps on BDNF and TrkB expressions in the hippocampus}

To verify the effects of Cordyceps on the expressions of BDNF and $\operatorname{TrkB}$, the relative expressions of BDNF and TrkB were ascertained (Fig. 6). When the level of BDNF (15 kDa) in the sham-operation group was set at 1.00, the level of BDNF was $0.58 \pm 0.04$ in the cerebral ischemia-induced group, $1.01 \pm 0.08$ in the cerebral ischemia-induced and $0.001-\mathrm{mg} / \mathrm{kg}$ Cordyceps-treated group, $0.81 \pm 0.02$ in the cerebral ischemia-induced and $0.01-\mathrm{mg} / \mathrm{kg}$ Cordyceps-treated group, and $0.61 \pm 0.02$ in the cerebral ischemia-induced and $0.1-\mathrm{mg} / \mathrm{kg}$ Cordyceps-treated group.

When the level of $\operatorname{TrkB}(95-145 \mathrm{kDa})$ in the sham-operation group was set at 1.00 , the level of $\operatorname{TrkB}$ was $0.28 \pm 0.07$ in the cerebral ischemia-induced group, $0.85 \pm 0.02$ in the cerebral ischemia-induced and $0.001-\mathrm{mg} / \mathrm{kg}$ Cordyceps-treated group, $0.67 \pm 0.05$ in the cerebral ischemia-induced and $0.01-\mathrm{mg} / \mathrm{kg}$ Cordyceps-treated group, and $0.61 \pm 0.04$ in the cerebral ischemia-induced and $0.1-\mathrm{mg} / \mathrm{kg}$ Cordyceps-treated group.

These results showed that ischemic insults suppressed BDNF and TrkB expressions in the hippocampus, and Cordyceps treatment enhanced BDNF and TrkB expressions in the cerebral ischemia gerbils.

\section{DISCUSSION}

Cerebral ischemia deprives oxygen and glucose in the brain, 


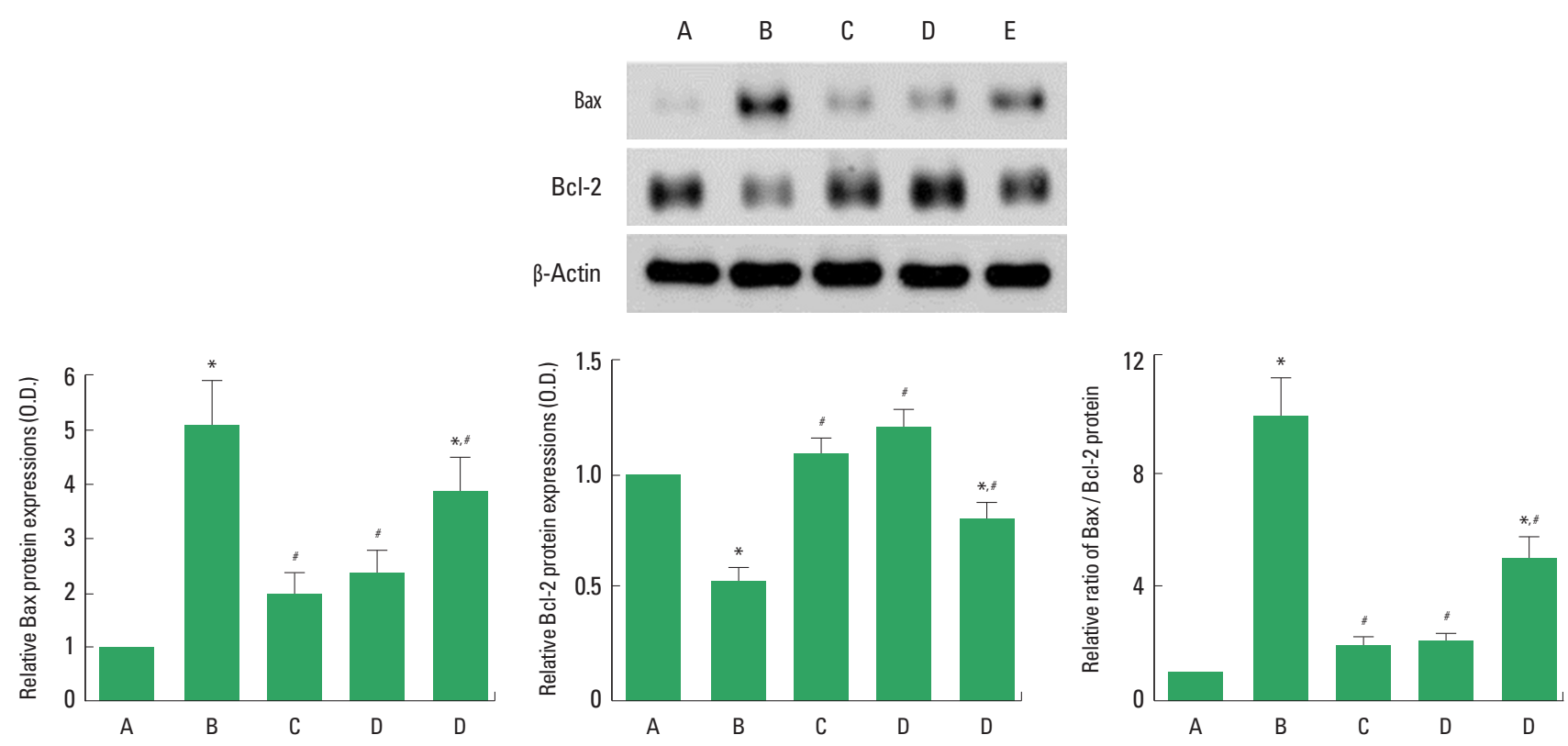

Fig. 5. Effects of Cordyceps on Bax and Bcl-2 expressions in the hippocampus. Actin was used as an internal control (46 kDa). Upper: The results of band detection using the enhanced chemiluminescence detection kit. (A) Sham-operation group, (B) cerebral ischemia-induced group, (C) cerebral ischemia-induced and 0.001-mg/ kg Cordyceps-treated group, (D) cerebral ischemia-induced and 0.01-mg/kg Cordyceps-treated group, (E) cerebral ischemia-induced and 0.1-mg/kg Cordyceps-treated group. Lower: The relative expressions of Bax and Bcl-2 proteins in each group. ${ }^{*} P<0.05$ compared to the sham-operation group. ${ }^{\sharp} P<0.05$ compared to the cerebral ischemia-induced group.
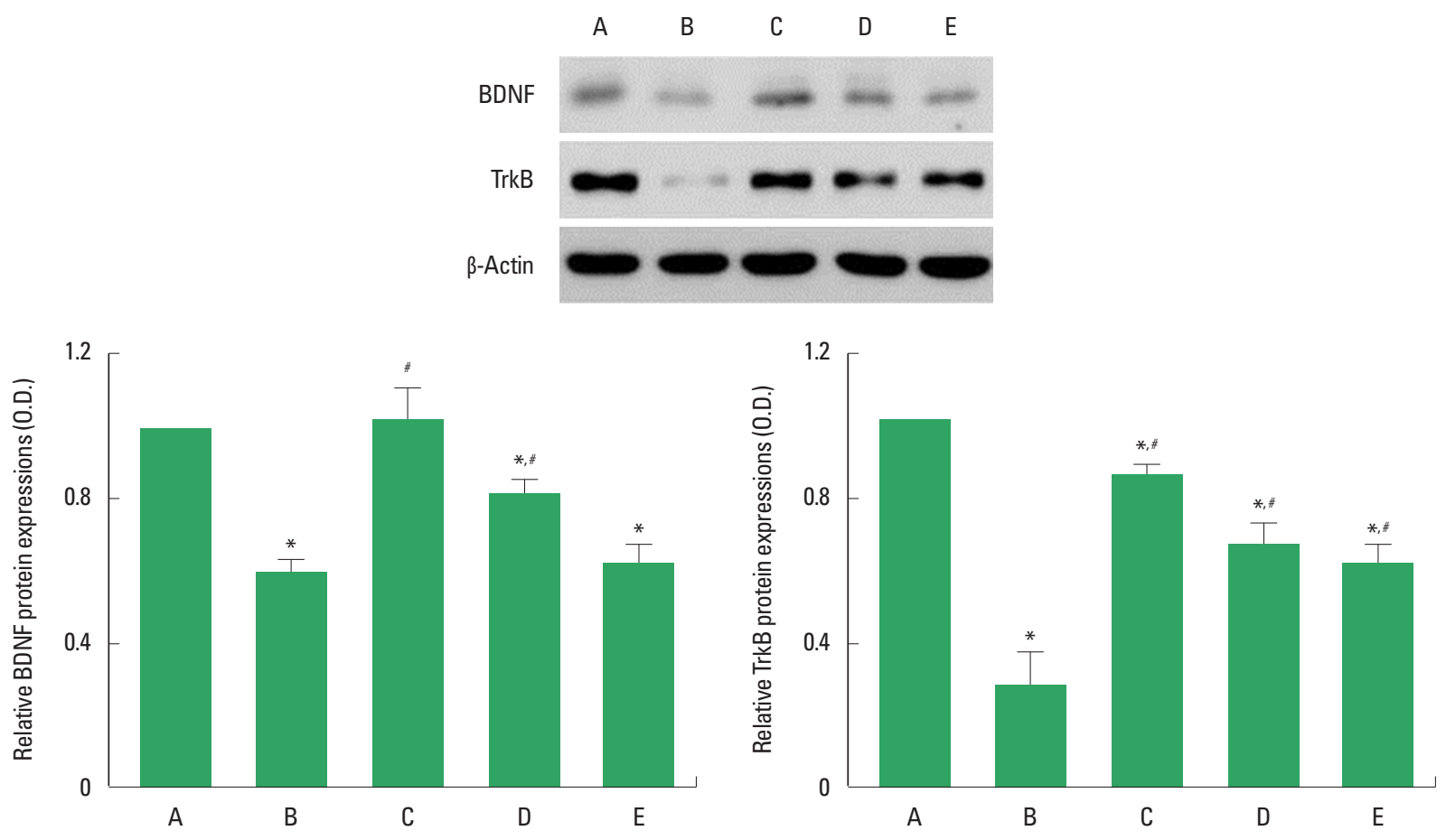

Fig. 6. Effects of Cordyceps on brain-derived neurotrophic factor (BDNF) and tyrosin kinase B (TrkB) expressions in the hippocampus. Actin was used as an internal control (46 kDa). Upper: The results of band detection using the enhanced chemiluminescence detection kit. (A) Sham-operation group, (B) cerebral ischemia-induced group, (C) cerebral ischemia-induced and 0.001-mg/kg Cordyceps-treated group, (D) cerebral ischemia-induced and 0.01-mg/kg Cordyceps-treated group, (E) cerebral ischemia-induced and $0.1-\mathrm{mg} / \mathrm{kg}$ Cordyceps-treated group. Lower: The relative expressions of BDNF and TrkB proteins in each group. ${ }^{*} P<0.05$ compared to the sham-operation group. ${ }^{\sharp} P<0.05$ compared to the cerebral ischemia-induced group. 
causing tissue infarction and neuronal cell death (Benchoua et al., 2001; Ko et al., 2009). Apoptosis is the major pathway of cell death after cerebral ischemia injury (Mattson et al., 2001). The morphological characteristics of apoptosis include cell shrinkage, chromatin condensation, membrane blebbing, internucleosomal DNA fragmentation, and the formation of apoptotic bodies (Li et al., 1995). Moreover, caspase- 3 is up-regulated and activated in the early stage of apoptosis following ischemia (Benchoua et al., 2001; Sim et al., 2004). The numbers of TUNEL-positive cells and caspase-3-positive cells in the hippocampus were increased in the multiple sclerosis rats, suggesting enhancement of apoptosis (Jin et al., 2014). In the present study, the numbers of TUNEL -positive and caspase-3-positive cells in the hippocampal CA1 region were increased following cerebral ischemic insult. This indicates that cerebral ischemia induced apoptotic neuronal cell death in the hippocampal CA1 region.

The Bcl-2 family of proteins, which includes $\mathrm{Bcl}-2$ and $\mathrm{Bcl}-\mathrm{XL}$, plays an important role in the regulation of apoptosis in the nervous system (Upadhyay et al., 2003). Bcl-2 inhibits apoptosis by preventing the release of cytochrome $\mathrm{c}$ from mitochondria. However, $\mathrm{Bcl}-2$ and $\mathrm{Bcl}-\mathrm{XL}$ form heterodimers with the main pro-apoptotic member, Bax, and in so doing, they incapacitate Bax activity (Kuwana and Newmeyer, 2003). That is, the Bax to $\mathrm{Bcl}-2$ balance is the crucial factor for the determination of apoptosis. Carloni et al. (2008) reported that hypoxic ischemic injury in the brain increased Bax level while $\mathrm{Bcl}-2$ level was decreased beginning $6 \mathrm{hr}$ after the insult. In the present study, cerebral ischemic injury increased Bax expression, whereas decreased Bcl-2 expression. Therefore, the ratio of $\mathrm{Bax}$ to $\mathrm{Bcl}-2$ was increased, indicating that cerebral ischemic injury initiated apoptotic neuronal cell death in the hippocampus.

Increased cell proliferation in the hippocampal dentate gyrus and cerebral cortex after ischemia has been previously documented (Liu et al., 1998; Sim et al., 2004). Ko et al. (2009) reported that cell proliferation in the dentate gyrus of gerbils was increased by induction of global ischemia. In the present study, the number of BrdU-positive cells in the hippocampal dentate gyrus was increased following cerebral ischemia. Enhanced cell proliferation in the dentate gyrus is known as a compensatory adaptive response to excessive apoptosis (Liu et al., 1998; Sim et al., 2004).

BDNF has been shown to play a role in both protection and recovery of functions after stroke. Especially, BDNF is important intercellular signal mediating neurogenesis, synaptic plasticity, and cell survival (Kim et al., 2010; Lee and Son, 2009). Decreased BDNF expression in the hippocampus caused memory impair- ment in elderly (Kim et al., 2010). Suppression of BDNF and TrkB expression in the hippocampus was closely associated with short-term memory impairment (Kim et al., 2015). Expression of BDNF was beneficial for the survival of neurons through antiapoptotic effect in the ischemic/reperfusion model (Fan et al., 2015). In the present study, BDNF and TrkB expressions in the hippocampus were decreased following cerebral ischemic injury.

Cordyceps is known to exert therapeutic effects by inducing apoptosis (Tuli et al., 2013). Cordyceps induced apoptosis in human colorectal cancer cell lines by enhancing the protein expression levels of JNK, p38 kinase, and Bcl-2 pro-apoptotic molecules (He et al., 2010). Cordyceps-mediated apoptosis in the breast cancer cell line increased mitochondrial translocation of Bax and the released cytochrome c (Choi et al., 2011).

In the present study, Cordyceps showed therapeutic effects through inhibiting apoptosis. Decrement in the ratio of Bax to $\mathrm{Bcl}-2$ in the hippocampus represents inhibition of hippocampal neuronal apoptosis (Kim et al., 2010). Our study showed that Cordyceps suppressed the cerebral ischemia-induced increment in DNA fragmentation and caspase-3 expression in the hippocampal CA1 region. Furthermore, Cordyceps treatment suppressed Bax expression and enhanced $\mathrm{Bcl}-2$ expression in the hippocampus, resulting in a decrement of $\mathrm{Bax}$ to $\mathrm{Bcl}-2$ ratio. Cordyceps also suppressed cerebral ischemia-induced cell proliferation in the dentate gyrus due to the reduced apoptotic neuronal cell death. These results showed that Cordyceps inhibited cerebral ischemia-induced apoptosis in the hippocampus.

Cordyceps enhanced neurotrophic factors, such as BDNF and nerve growth factor (NGF) in the chronic stress-exposed animal models (Tianzhu et al., 2014). In the present study, Cordyceps treatment also enhanced BDNF and TrkB expressions in the hippocampus. These results showed that Cordyceps possesses memory enhancing effect.

In this study, we evaluated the effect of Cordyceps on cerebral ischemia-induced short-term memory impairment using a stepdown avoidance task. We found that latency was shortened by induction of transient global ischemia, in contrast, latency was improved by Cordyceps treatment. The enhancing effect of Cordyceps on short-term memory can be ascribed to the inhibition on apoptotic neuronal cell death and increasing on BDNF and TrkB expressions. These effects of Cordyceps appeared most potently at lowest dosage used in this study. Here in this study, we suggest the possibility that the Cordyceps overcomes cerebral ischemia-induced neuronal apoptosis, thus facilitates recovery following cerebral ischemic injury. 


\section{CONFLICT OF INTEREST}

No potential conflict of interest relevant to this article was reported.

\section{ACKNOWLEDGMENTS}

This work was supported by the National Research Foundation of Korea Grant funded by the Korean Government (NRF2014S1A5B5A02016790).

\section{REFERENCES}

Benchoua A, Guégan C, Couriaud C, Hosseini H, Sampaïo N, Morin D, Onténiente B. Specific caspase pathways are activated in the two stages of cerebral infarction. J Neurosci 2001;21:7127-7134.

Carloni S, Buonocore G, Balduini W. Protective role of autophagy in neonatal hypoxia-ischemia induced brain injury. Neurobiol Dis 2008; 32:329-339.

Choi S, Lim MH, Kim KM, Jeon BH, Song WO, Kim TW. Cordycepin-induced apoptosis and autophagy in breast cancer cells are independent of the estrogen receptor. Toxicol Appl Pharmacol 2011;257:165-173.

Cohen GM. Caspases: the executioners of apoptosis. Biochem J 1997; 326(Pt 1):1-16.

Fan $M$, Jin W, Zhao H, Xiao Y, Jia Y, Yin Y, Jiang X, Xu J, Meng N, Lv P. Lithium chloride administration prevents spatial learning and memory impairment in repeated cerebral ischemia-reperfusion mice by depressing apoptosis and increasing BDNF expression in hippocampus. Behav Brain Res 2015;291:399-406.

Gavrieli Y, Sherman Y, Ben-Sasson SA. Identification of programmed cell death in situ via specific labeling of nuclear DNA fragmentation. J Cell Biol 1992;119:493-501.

He W, Zhang MF, Ye J, Jiang TT, Fang X, Song Y. Cordycepin induces apoptosis by enhancing JNK and p38 kinase activity and increasing the protein expression of Bcl-2 pro-apoptotic molecules. J Zhejiang Univ Sci B 2010;11:654-660.

Jeong JW, Jin CY, Kim GY, Lee JD, Park C, Kim GD, Kim WJ, Jung WK, Seo SK, Choi IW, Choi YH. Anti-inflammatory effects of cordycepin via suppression of inflammatory mediators in BV2 microglial cells. Int Immunopharmacol 2010;10:1580-1586.

Jin JJ, Ko IG, Kim SE, Shin MS, Kim SH, Jee YS. Swimming exercise ameliorates multiple sclerosis-induced impairment of short-term memory by suppressing apoptosis in the hippocampus of rats. J Exerc Rehabil 2014;10:69-74

Ke XJ, Zhang JJ. Changes in HIF-1 $\alpha$, VEGF, NGF and BDNF levels in ce- rebrospinal fluid and their relationship with cognitive impairment in patients with cerebral infarction. J Huazhong Univ Sci Technolog Med Sci 2013;33:433-437.

Kim K, Sung YH, Seo JH, Lee SW, Lim BV, Lee CY, Chung YR. Effects of treadmill exercise-intensity on short-term memory in the rats born of the lipopolysaccharide-exposed maternal rats. J Exerc Rehabil 2015;11:296-302.

Kim SE, Ko IG, Kim BK, Shin MS, Cho S, Kim CJ, Kim SH, Baek SS, Lee EK, Jee YS. Treadmill exercise prevents aging-induced failure of memory through an increase in neurogenesis and suppression of apoptosis in rat hippocampus. Exp Gerontol 2010;45:357-365.

Kim SE, Ko IG, Shin MS, Kim CJ, Jin BK, Hong HP, Jee YS. Treadmill exercise and wheel exercise enhance expressions of neutrophic factors in the hippocampus of lipopolysaccharide-injected rats. Neurosci Lett 2013;538:54-59.

Ko IG, Shin MS, Kim BK, Kim SE, Sung YH, Kim TS, Shin MC, Cho HJ, Kim SC, Kim SH, Kim KH, Shin DH, Kim CJ. Tadalafil improves short-term memory by suppressing ischemia-induced apoptosis of hippocampal neuronal cells in gerbils. Pharmacol Biochem Behav 2009;91:629-635

Kuwana T, Newmeyer DD. Bcl-2-family proteins and the role of mitochondria in apoptosis. Curr Opin Cell Biol 2003;15:691-699.

Lee E, Son H. Adult hippocampal neurogenesis and related neurotrophic factors. BMB Rep 2009;42:239-244.

Lee MH, Kim H, Kim SS, Lee TH, Lim BV, Chang HK, Jang MH, Shin MC, Shin MS, Kim CJ. Treadmill exercise suppresses ischemia-induced increment in apoptosis and cell proliferation in hippocampal dentate gyrus of gerbils. Life Sci 2003;73:2455-2465.

Leker RR, Shohami E. Cerebral ischemia and trauma-different etiologies yet similar mechanisms: neuroprotective opportunities. Brain Res Brain Res Rev 2002;39:55-73.

Li Y, Chopp M, Jiang N, Zhang ZG, Zaloga C. Induction of DNA fragmentation after 10 to 120 minutes of focal cerebral ischemia in rats. Stroke 1995;26:1252-1257.

Liu J, Solway K, Messing RO, Sharp FR. Increased neurogenesis in the dentate gyrus after transient global ischemia in gerbils. J Neurosci 1998;18:7768-7778.

Mattson MP, Duan W, Pedersen WA, Culmsee C. Neurodegenerative disorders and ischemic brain diseases. Apoptosis 2001;6:69-81.

Sairanen M, Lucas G, Ernfors P, Castrén M, Castrén E. Brain-derived neurotrophic factor and antidepressant drugs have different but coordinated effects on neuronal turnover, proliferation, and survival in the adult dentate gyrus. J Neurosci 2005;25:1089-1094

Sim YJ, Kim SS, Kim JY, Shin MS, Kim CJ. Treadmill exercise improves short-term memory by suppressing ischemia-induced apoptosis of 
neuronal cells in gerbils. Neurosci Lett 2004;372:256-261.

Simon D, Nascimento RI, Filho EM, Bencke J, Regner A. Plasma brain-derived neurotrophic factor levels after severe traumatic brain injury. Brain Inj 2016;30:23-28.

Sugawara T, Noshita N, Lewén A, Gasche Y, Ferrand-Drake M, Fujimura M, Morita-Fujimura Y, Chan PH. Overexpression of copper/zinc superoxide dismutase in transgenic rats protects vulnerable neurons against ischemic damage by blocking the mitochondrial pathway of caspase activation. J Neurosci 2002;22:209-217.

Tianzhu Z, Shihai Y, Juan D. Antidepressant-like effects of cordycepin in a mice model of chronic unpredictable mild stress. Evid Based Complement Alternat Med 2014;2014:438506.

Tuli HS, Sharma AK, Sandhu SS, Kashyap D. Cordycepin: a bioactive me- tabolite with therapeutic potential. Life Sci 2013;93:863-869.

Upadhyay D, Panduri V, Ghio A, Kamp DW. Particulate matter induces alveolar epithelial cell DNA damage and apoptosis: role of free radicals and the mitochondria. Am J Respir Cell Mol Biol 2003;29:180-187.

Yamaguchi Y, Kagota S, Nakamura K, Shinozuka K, Kunitomo M. Antioxidant activity of the extracts from fruiting bodies of cultured Cordyceps sinensis. Phytother Res 2000;14:647-649.

Yao LH, Yu HM, Xiong QP, Sun W, Xu YL, Meng W, Li YP, Liu XP, Yuan $\mathrm{CH}$. Cordycepin decreases compound action potential conduction of frog sciatic nerve in vitro involving $\mathrm{Ca}(2+)$-dependent mechanisms. Neural Plast 2015;2015:927817.

Yue K, Ye M, Zhou Z, Sun W, Lin X. The genus Cordyceps: a chemical and pharmacological review. J Pharm Pharmacol 2013;65:474-493. 